\title{
PENGEMBANGAN PERANGKAT PEMBELAJARAN MODEL NESTEDBERBASIS INKUIRI TERBIMBING UNTUK MENINGKATKAN PEMAHAMAN KONSEP, THINKING SKILL, DAN SOCIAL SKILL PADA SISWA SMP
}

\author{
Fitrotul Choiriyah $^{1)}$, Madlazim ${ }^{2)}$, Tjipto Haryono ${ }^{3)}$ \\ 1) Pendidikan Sains, Pascasarjana, Universitas Negeri Surabaya \\ 2) Dosen Pendidikan Sains, Pascasarjana, Universitas Negeri Surabaya \\ ${ }^{3)}$ Dosen Pendidikan Sains, Pascasarjana, Universitas Negeri Surabaya \\ Email: pitchoiriyah@gmail.com
}

\begin{abstract}
Abstrak: Telah dilakukan penelitian dengan mengembangkan perangkat pembelajaran (RPP, LKS, Buku ajar siswa, Tes Pemahaman Konsep, Thinking skill dan Social Skill) model nested berbasis inkuiri terbimbing dengan pengembangan 4D untuk meningkatkan pemahaman konsep, thinking skill dan social skill pada pokok bahasan cahaya. Sasaran penelitian adalah perangkat pembelajaran yang diujicobakan pada 32 siswa SMP dengan rancangan One-Group Pretest-Posttest Design. Analisis data secara kuantitatif-kualitatif dengan hasil: (a) validitas perangkat ketegori sangat valid; (b) keterlaksanaan pembelajaran sangat baik; (c) respon siswa positif; (d) pemahaman konsep meningkat (kriteria tinggi); (e) thinking skill meningkat (kriteria tinggi); (f) social skill meningkat di setiap pertemuan. Simpulan penelitian ini, bahwa perangkat pembelajaran model nested berbasis inkuiri terbimbing terbukti layak dan dapat meningkatkan pemahaman konsep, thinking skill, dan social skill pada siswa SMP.
\end{abstract}

Kata kunci :Nested, Inkuiri terbimbing, Pemahaman Konsep, Thinking skill, Social Skill

\begin{abstract}
This research was done by developing learning materials (lesson plans, student's worksheets, textbooks students, test understanding of the concept, Thinking skill and Social Skill) nested models based guided inquiry by using $4 D$ development model to improve the understanding of the concept, thinking skills and social skills on the subject of light. The objective of this research is trial learning materials for 32 of junior high school's students with the design of the one-group pretest-posttest design. Result was analyzed by descriptive quantitative - qualitative with: (a) validity of learning material is very valid category; (b) learning realization with good category; (c) the students response are positive; (d) student's understanding of the concept is increased (high criteria); (e) thinking skill is increased (high criteria); (f) social skill increased in every meeting. In conclusions of this research, the nested model based learning guided inquiry concepts can improve the understanding concept, thinking skills, and social skill of junior high school.
\end{abstract}

Keywords :Nested, Guided Inquiry, Concept Understanding, Thinking Skill, Social Skill

\section{PENDAHULUAN}

Pendidikan yang sedang berkembang diIndonesia saat ini bisa dikatakan lebih baik dari waktu ke waktu.Tetapi jika diamati lebih jauh,terdapat sebuah permasalahan yang cukup komplek, yaitu hilangnya substansi utama dari pendidikan itu sendiri. Menurut Undang-undang Nomor 20 Tahun 2003 tentang Sistem Pendidikan Nasional, Pasal 1 ayat 1 bahwa "Pendidikan adalah usaha sadar dan terencana untuk mewujudkan suasana belajar dan proses pembelajaran agar peserta didik secara aktif mengembangkan potensi dirinya untuk memiliki kekuatan spiritual keagamaan, pengendalian diri, kepribadian, kecerdasan, akhlak mulia, serta keterampilan yang diperlukan dirinya, masyarakat, bangsa dan negara". Berdasarkan pernyataan tersebut dapat dikatakan bahwa pendidikan merupakan proses pembelajaran yang diarahkan kepada perkembangan peserta didik untuk memiliki kekuatan spiritual, kecerdasan, akhlak mulia, serta keterampilan yang diperlukan dirinya, masyarakat, bangsa dan negara.

Siswa kesulitan dalam mengembangkan keterampilan berpikir sehingga siswa tidak dapat menerapkan konsep atau teori yang dipelajari di dalam kehidupannya sehari-hari. Selain itu, persoalan lain yang dirasakan oleh guru, yaitu guru belum banyak mengetahui model-model pembelajaran inovatif yang menciptakan suasana belajar lebih interaktif serta keterbatasan waktu guru mata pelajaran IPA untuk dapat menyediakan perangkat pembelajaran dalam melatihkan thinking skill 
dan social skill. Hal lain dari riset yang dilakukan oleh TIMSS (Nur, 2012) menunjukkan siswa Indonesia berada pada peringkat amat rendah dalam thinking skill.

Mendesain pembelajaran yang menarik dan menyenangkan tidak hanya kepentingan untuk guru semata dalam melaksanakan tugasnya atau agar pelajaran yang diajarkan disenangi oleh peserta didik, namun juga berperan besar terhadap perkembangan pola pikir peserta didik yang merupakan generasi penerus bangsa Indonesia.Cara pembelajaran sains yang baik adalah bila dilakukan seperti bagaimana sains itu ditemukan (Ibrahim, 2008).

Perencanaan pembelajaran perlu dibuat sebaikbaiknya untuk memperoleh hasil yang maksimal. Menurut Arends (2012), bahwa proses perencanaan pembelajaran yang dibuat oleh guru dapat memberikan hubungan yang baik antara guru dan peserta didik dan juga dapat membantu peserta didik memahami tujuantujuan implisit yang terdapat dalam tugas-tugas yang diberikan kepada mereka. Dalam pembelajaran sains guru dituntut untuk dapat mengajak peserta didiknya untuk berinteraksi dengan apa yang sedang dipelajari. Berbagai konsep diajarkan sesuai dengan tingkat kemampuan peserta didik.Salah satu konsep yang diajarkan di Kelas VIII jenjang SMP adalah konsep cahaya.

Sejalan dengan tujuan untuk meningkatkan pemahaman siswa serta melatihkan thinking skill dan social skill maka digunakan model keterapaduan Nested. Model nested digunakan guru sebagai usaha untuk menanamkan standar proses, seperti thinking skill dan social skill, menjadi pelajaran konten mereka. Menjaga tujuan konten sebagai pusat pembelajaran dengan menambahkan focus thinking skill dan social skill dapat meningkatkan pengalaman belajar secara keseluruhan. Salah satu model yang dipandang sejalan dengan prinsip keterpaduan Nested serta dapat melatihkan thinking skill dan social skill siswa adalah model inkuiri terbimbing. Model pembelajaran inkuiri terbimbing terdiri dari enam tahap, yaitu: (a) perencanaan, (b) mendapatkan informasi, (c) memproses informasi, (d) membuat informasi, (e) mengkomunikasikan informasi, dan (f) mengevaluasi (Branch \& Oberg, 2004).Model inkuiri terbimbing menawarkan penyelidikan terintegrasi yang direncanakan dan dipandu oleh guru, memungkinkan siswa untuk mendapatkan lebih pemahaman subyek isi kurikulum dan informasi konsep. Mengembangkan keterampilan dan kemampuan yang diperlukan untuk kerja dan kehidupan sehari-hari

\section{METODE PENELITIAN}

Jenis penelitian ini adalah penelitian pengembangan (development research), karena penelitian tidak bermaksud menguji teori yang ada tetapi untuk mengembangkan suatu perangkat pembelajaran materi cahaya. Perangkat yang dikembangkan berupa rencana pelaksanaan pembelajaran (RPP), buku ajar siswa (BAS), lembar kegiatan siswa (LKS), dan tes pemahaman konsep (TPK), tes thinking skill (TTS) dan social skill pada kompetensi dasar (KD) 3.11 yaitu : 3.11. Mendeskripsikan sifat-sifat cahaya, pembentukan bayangan, serta aplikasinya untuk menjelaskan penglihatan manusia, proses pembentukan bayangan pada mata serangga dan prinsip kerja alat optik. Penelitian ini menggunakan pendekatan pre experiment design dan juga tergolong penelitian deskriptif kuantitatif, karena hasil penelitian dianalisis dengan teknik statistik dan dijabarkan dalam bentuk naratif. Pola :

\begin{tabular}{|c|c|c|}
\hline Pretest & $\begin{array}{c}\text { Perlakuan } \\
\text { (Treatment) }\end{array}$ & Posttest \\
\hline $\mathrm{O}_{1}$ & $\mathrm{X}$ & $\mathrm{O}_{2}$ \\
\hline
\end{tabular}

Keterangan:

$\mathrm{O}_{1}=$ pretest atau uji awal yang dilakukan untuk mendeskripsikan hasil pemahaman konsep, thinking skill dan social skill siswa.

$\mathrm{X}=$ perlakuan dengan menerapkan perangkat pembelajaran model nested berbasis inkuiri terbimbing

$\mathrm{O}_{2}=$ posttest atau uji akhir yang dilakukan untuk mendeskripsikan hasil pemahaman konsep, thinking skill dan social skill setelah diterapkan perangkat pembelajaran nested berbasis inkuiri terbimbing.

Penelitian, pengembangan dan validasi media pembelajaran dilaksanakan di Universitas Negeri Surabaya dan diimplementasikan di SMP Negeri 1 Gresik Kabupaten Gresik. Implementasi dilaksanakan di kelas VIII A dengan sampel sebanyak 32 siswa pada bulan Juli 2016.

Pengembangan perangkat pembelajaran pada penelitian ini mengadaptasi pengembangan perangkat model 4D (four $D$ model). Pengembangan perangkat pembelajaran model 4D terdiri dari tahap pendefinisian (define), perancangan (design), pengembangan (develop) dan penyebaran (disseminate) (Thiagarajan \& Semmel, Semmel, 1974).

Metode pengumpulan data yang digunakan diantaranya: (1) metode observasi untuk memperoleh data keterlaksanaan pembelajaran, aktivitas dan social skill(2) metode tes yang digunakan untuk memperoleh data pemahaman konsep dan thinking skill; dan (3) metode angket digunakan untuk mendapatkan data respons siswa terhadap proses pembelajaran yang telah dilaksanakan.

Data tersebut dianalisis secara deskriptif kuantitatif dengan mendeskripsikan skor dalam setiap aspek yang 
diamati.Adapun kriteria persentase keterlaksanaan pembelajaran dinyatakan sebagai berikut:

Tabel 1. Kriteria Interpretasi Skor Keterlaksanaan RPP

\begin{tabular}{|c|c|}
\hline Skala Penilaian & Kategori \\
\hline $1,0-1,5$ & Tidak Baik \\
\hline $1,6-2,5$ & Kurang Baik \\
\hline $2,6-3,5$ & Baik \\
\hline $3,6-4,0$ & Sangat Baik \\
\hline
\end{tabular}

Nilai yang diperoleh pada tes pemahaman konsep dan thinking skill kemudian dikonversi berdasarkan Permendikbud RI No 53 Tahun 2015 dengan rentang sebagai berikut:

Tabel 2. Rentang Nilai Kompetensi Pengetahuan

\begin{tabular}{|c|c|}
\hline Rentang & Nilai \\
\hline $86-100$ & SangatBaik (A) \\
\hline $71-85$ & Baik (B) \\
\hline $56-70$ & Cukup (C) \\
\hline$\leq \mathbf{5 5}$ & Kurang(D) \\
\hline
\end{tabular}

Ketuntasan hasil belajar pengetahuan siswa secara individu ditetapkan dengan skor rerata 75. Skor ini berdasarkan nilai KKM yang ditetapkan di sekolah.

Sedangkan social skill dapat dinilai dengan skor yang disajikan pada Tabel 3 berikut ini:

Tabel 3.RentangNilai Social Skill Siswa

\begin{tabular}{|lll|l|}
\hline \multicolumn{3}{|c|}{ Nilai } & Predikat \\
\hline 3.85 & - & 4,00 & A \\
\hline 3.51 & - & 3.84 & A- \\
\hline 3.18 & - & 3.50 & B+ \\
\hline 2.85 & - & 3.17 & B \\
\hline 2.51 & - & 2.84 & B- \\
\hline 2.18 & - & 2.50 & C+ \\
\hline 1.85 & - & 2.17 & C \\
\hline 1.51 & - & 1.84 & C- \\
\hline 1.18 & - & 1.50 & D+ \\
\hline 1.00 & - & 1.17 & D \\
\hline
\end{tabular}

Untuk mengetahui peningkatan pemahaman konsep dan thinking skill siswa pada pretest dan posttest dapat dilakukan analisis deskriptif berupa uji N-Gain ternormalisasi.Rumusan untuk menganalisisnya:

$<\mathrm{g}>=\frac{\text { Spost-Spre }}{\text { Smax }- \text { Spre }}$

(Hake, 1999)

Keterangan:

$\begin{array}{ll}\langle\mathrm{g}\rangle & =\text { Nilai peningkatan } \\ \text { Spost } & =\text { Nilai posttest } \\ \text { Spre } & =\text { Nilai Pretest } \\ \text { Smax } & =\text { Nilai maksimal }\end{array}$

Kemudian Gain-ternomalisasi diinterpretasikan sesuai dengan kriteria menurut Hake yaitu:

$$
\begin{array}{ll}
\langle\mathrm{g}>>0,7 & =\text { tinggi } \\
0,7<<\mathrm{g}><0,3 & =\text { sedang } \\
\langle\mathrm{g}><0,3 & =\text { rendah }
\end{array}
$$

Aktivitas siswa adalah segala aktivitas yang dilakukan siswa selama KBM berlangsung dan dinilai oleh dua orang pengamat dengan menggunakan Instrumen. Data yang diperoleh selanjutnya dianalisis deskriptif kuantitatif dengan menggunakan rumus percentage of agreement sebagai berikut:

$$
\mathrm{P}=\frac{\sum \mathrm{A}}{\sum \mathrm{N}} \times 100 \%
$$

Keterangan: $\mathrm{P}=$ Persentase aktivitas siswa

$$
\begin{aligned}
& \begin{array}{c}
\sum \mathrm{A}=\text { Jumlah frekuensi tiap aktivitas yang } \\
\text { muncul }
\end{array} \\
& \sum \mathrm{N}=\text { Jumlah total frekuensi aktivitas }
\end{aligned}
$$

Untuk menentukan percentage of agreement Instrumen Aktivitas Siswa, digunakan rumus percentage of agreement sebagai berikut:

$$
\mathrm{R}=\left[1-\frac{\mathrm{A}-\mathrm{B}}{\mathrm{A}+\mathrm{B}}\right] \times 100 \%
$$

Keterangan: $\mathrm{R}=$ Koefisien percentage of agreement

$$
\begin{aligned}
\mathrm{A}= & \text { Frekuensi aspek tingkah laku yang } \\
& \text { teramati oleh pengamat dengan } \\
& \text { memberikan frekuensi tinggi } \\
\mathrm{B}= & \text { Frekuensi aspek tingkah laku yang } \\
& \text { teramati oleh pengamat dengan } \\
& \text { memberikan frekuensi rendah }
\end{aligned}
$$

Instrumen Pengamatan Aktivitas Siswa dikatakan reliabel, jika nilai percentage of agreementnya $\geq 75 \%$ (Borich, 1994).

Selain itu, untuk mengetahui respon siswa dianalisis dengan menggunakan rumus sebagai berikut:

$$
\mathrm{P}=\frac{\mathrm{f}}{\sum \mathrm{N}} \mathrm{x} 100 \%
$$

$\mathrm{P} \quad=$ Persentase respon siswa

$\mathrm{f} \quad=$ Jumlah siswa yang menjawab positif

$\sum \mathrm{N}=$ jumlah seluruh skor respon siswa

(Sugiyono, 2013)

Tabel 4. KriteriaInterpretasi Skor ResponSiswa

\begin{tabular}{cc}
\hline Rerata Skor & Kategori \\
\hline $0-20 \%$ & Sangat lemah \\
\hline $21-40 \%$ & Lemah \\
\hline $41-60 \%$ & Cukup \\
\hline $61-80 \%$ & Kuat \\
\hline $81-100 \%$ & SangatKuat \\
\hline & (Riduwan, 2010)
\end{tabular}

\section{HASIL DAN PEMBAHASAN}

Keterlaksanaan pembelajaran dilakukan untuk mengetahui terlaksana tidaknya rencana pelaksanaan pembelajaran (RPP) yang telah disusun oleh peneliti dalam proses pembelajaran pada materi cahaya.Data keterlaksanaan proses pembelajaran diperoleh dengan menggunakan lembar pengamatan keterlaksanaan pembelajaran. Hasil skor rata-rata penilaian 
keterlaksanaan pembelajaran disajikan dalam dalam Gambar 1 berikut.

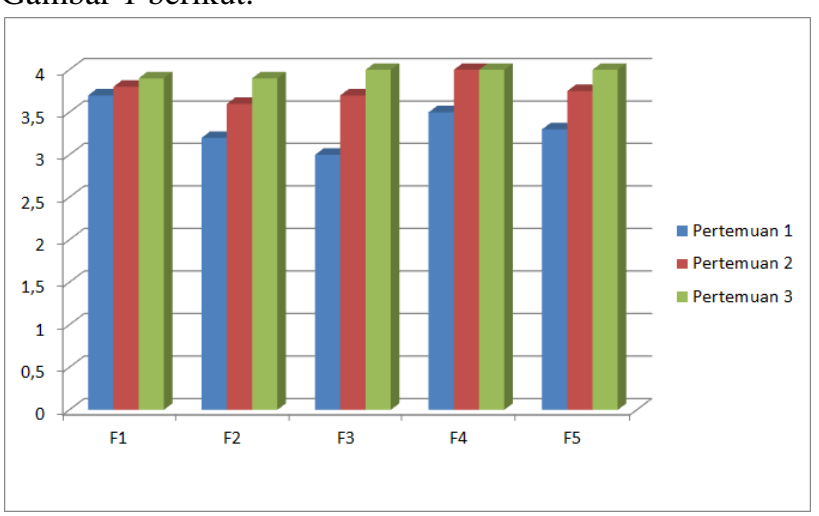

Gambar 1.DiagramKeterlaksanaan Pembelajaran

Keterangan:

F1 : Kegiatan awal

F2 : Kegiatan inti

F4 : Pengelolaan waktu

F3 : Kegiatan penutup

Berdasarkan Gambar 1 di atas dapat diketahui persentase keterlaksanaan pembelajaran pada pertemuan I, II dan III dengan Interval rata-rata skor keterlaksanaan pembelajaran 3,0 - 4,0 dengan kategori baik dan sangat baik. Sesuai dengan pendekatan inkuiri terbimbing, maka hampir semua kegiatan pembelajaran yang terdapat dalam RPP terpusat pada peserta didik, antara lain mereka diminta merumuskan masalah, melakukan kegiatan di LKS untuk membuktikan hipotesis yang mereka buat, kemudian aktif berdiskusi dan membuat simpulan. Semua kegiatan ini sesuai dengan filsafat pendidikan progrevisme yang dikembangkan oleh John Dewey yang menyatakan bahwa pendidikan berpusat pada anak didik. Tujuan pendidikan merupakan rekonstruksi pengalaman yang terus-menerus, agar peserta didik dapat berbuat sesuatu dan mampu mengadakan penyesuaian sesuai dengan tuntutan dari lingkungan (Levine \& Ornstein, 1985). Aliran pendidikan progrevisme merupakan salah satu aliran yang menjadi landasan bagi pembelajaran IPA terintegrasi.

Aktivitas yang diamati terbagi menjadi tiga kategori yaitu aktivitas yang dapat meningkatkan pemahaman konsep, thinking skill dan social skill, dan aktivitas lain yang tidak relevan dengan kegiatan belajar mengajar. Data yang diperoleh pada pertemuan pertama untuk kategori pemahaman konsep memperoleh persentase $44 \%$, yang terdiri atas menafsirkan $9 \%$, memberi contoh $11 \%$, merangkum $12 \%$, dan menjelaskan 12\%. Data tersebut menunjukkan bahwa aktivitas merangkum dan menjelaskan sangat dominan dibandingkan aktivitas lainnya, hal ini dipengaruhi pada praktikum pertama, siswa melakukan aktivitas merangkum dan menjelaskan hukum pemantulan cahaya. Pada kategori melatihkan thinking skill memperoleh persentase $36 \%$ yang terdiri atas memprediksi $10 \%$, menyimpulkan 11\%, membandingkan $9 \%$ dan hipotesa 6\%. Data tersebut menunjukkan menyimpulkan sangat dominan dibandingkan aktivitas yang lain, hal ini dipengaruhi pada praktikum pertama siswa harus dapat membuat kesimpulan dari hasil praktikum. Sedangkan yang paling rendah adalah membuat hipotesis, hal ini dikarenakan siswa masih kesulitan untuk membuat hipotesis dari sebuah percobaan. Kategori yang ketiga adalah melatihkan social skill memperoleh persentase $19 \%$ yang terdiri atas menimbulkan rasa ingin tahu $11 \%$ dn mengemukakan ide $8 \%$. Data tersebut menunjukkan rasa ingin tahu siswa sangat dominan dikarenakan praktikum yang dilakukan memerlukan penggalian informasi yang lebih mendalam untuk membuat kesimpulan. Sedangkan mengemukakan ide masih rendah dikarenakan siswa masih sedikit canggung jika berbicara di depan teman-temannya. Aktivitas yang tidak relevan pada pertemuan pertama ini terjadi karena ada siswa yang masih belum terampil menggunakan alat untuk praktikum dan masih terdapatnya siswa yang berpindah atau sekedar hanya melihat kelompok lain.

Pada pertemuan kedua untuk kategori pemahaman konsep memperoleh persentase $42 \%$, yang terdiri atas menafsirkan $11 \%$, memberi contoh $9 \%$, merangkum $11 \%$, dan menjelaskan $11 \%$. Data tersebut menunjukkan persentase yang relatif seimbang, hal ini dilakukan agar ketrampilan yang diperoleh peserta didik dapat maksimal karena tidak ada yang dominan dilatihkan. Pada kategori melatihkan thinking skill memperoleh persentase 37\% yang terdiri atas memprediksi 10\%, menyimpulkan 9\%, membandingkan 9\% dan membuat hipotesis 9\%. Data tersebut menunjukkan memprediksi sangat dominan dibandingkan aktivitas yang lain, hal ini dipengaruhi pada praktikum kedua siswa harus dapat memprediksi letak bayangan benda pada lensa cembung. Pada aktivitas membuat hipotesis sudah ada peningkatan dibandingkan pertemuan pertama, hal ini diperoleh karena adanya evaluasi pada saat pertemuan pertama. Kategori yang ketiga adalah melatihkan social skill memperoleh persentase $21 \%$ yang terdiri atas menimbulkan rasa ingin tahu $11 \%$ dan mengemukakan ide $10 \%$. Data tersebut menunjukkan persentase yang relatif seimbang, hal ini dilakukan agar ketrampilan yang diperoleh peserta didik dapat maksimal karena tidak ada yang dominan dilatihkan. Aktivitas yang tidak relevan pada pertemuan kedua ini sudah tidak muncul.

Pada pertemuan ketiga untuk kategori pemahaman konsep memperoleh persentase $40 \%$, yang terdiri atas menafsirkan $10 \%$, memberi contoh $10 \%$, merangkum 10\%, dan menjelaskan 10\%. Data tersebut menunjukkan persentase yang seimbang, hal ini dilakukan agar ketrampilan yang diperoleh peserta didik dapat maksimal karena tidak ada yang dominan dilatihkan. Pada kategori 
melatihkan thinking skill memperoleh persentase $28 \%$ yang terdiri atas memprediksi $9 \%$, menyimpulkan $10 \%$, membandingkan $9 \%$ dan membuat hipotesis $10 \%$. Data tersebut menunjukkan persentase yang relatif seimbang, sehingga siswa memperoleh seluruh ketrampilan semaksimal mungkin. Pada aktivitas membuat hipotesis sudah bagus dibandingkan pertemuan kedua, sehingga proses sains bisa berjalan. Kategori yang ketiga adalah melatihkan social skill memperoleh persentase $24 \%$ yang terdiri atas menimbulkan rasa ingin tahu $12 \%$ dan mengemukakan ide $12 \%$. Data tersebut menunjukkan persentase yang seimbang, hal ini dilakukan agar ketrampilan yang diperoleh peserta didik dapat maksimal karena tidak ada yang dominan dilatihkan. Aktivitas yang tidak relevan pada pertemuan kedua ini sudah tidak muncul.

Pada saat pembelajaran hasil pretest diperoleh ratarata skor 32 dengan kategori rendah, sedangkan rata-rata skor posttest tingkat pemahaman konsep siswa adalah 89 dengan kategori tinggi. Perhitungan $N$-gain menunjukan rata-rata 0,84 dengan kriteria tinggi. Peningkatan skor pemahaman konsep cahaya pretest dan posttest menerima pembelajaran menggunakan model nested berbasis inkuiri terbimbing dapat ditunjukkan pada Gambar 2 berikut ini:

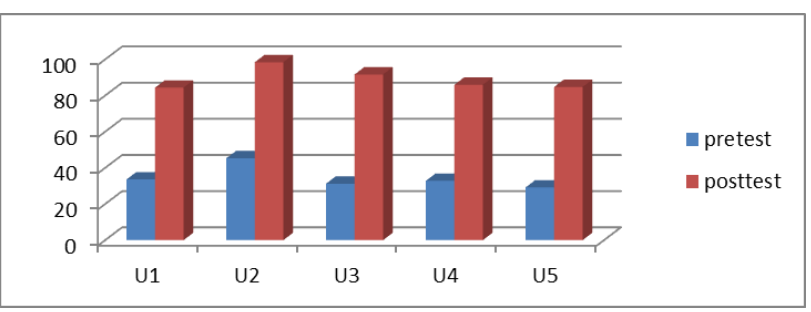

Keterangan:

Gambar 2.Diagram tes pemahaman konsep siswa

$\begin{array}{ll}\text { U1: interpretasi } & \text { U4:membandingkan } \\ \text { U2: mencontohkan } & \text { U5:menjelaskan } \\ \text { U3: mengklasifikasikan } & \end{array}$

Nilai peningkatan persentase pamahaman konsep peserta didik saat posttest menunjukkan bahwa pembelajaran yang dilaksanakan guru berlangsung dengan baik dan dapat meningkatkan pemahaman konsep peserta didik. Hal ini sejalan dengan respon peserta didik saat pembelajaran, dimana rata-rata peserta didik memberikan respon yang positif (sangat baik) terhadap proses belajar mengajar yang dilaksanakan. Soal tes pemahaman konsep yang dibuat terdiri atas 20 soal dalam bentuk soal pilihan ganda.

Efek pembelajaran dapat diketahui dengan menganalisis tingkat sensitivitas butir soal (Gronlund, 1995). Sensitivitas butir soal diukur dengan jumlah siswa yang menjawab benar pada pretest dan posttest. Pada penelitian ini analisis sensitivitas butir soal dilakukan pada soal tes pemahaman konsep yang terdiri atas 20 soal uraian. Hasil analisis sensitivitas butir soal menunjukkan indeks sensitivitas sebesar 0.55 .

Menurut Crocker dan Algina (1986, dalam Ratumanan \& Laurens, 2011) indeks sensitivitas butir pada dasarnya merupakan ukuran seberapa baik soal tersebut membedakan antara peserta didik yang telah dan yang belum mengikuti pembelajaran. Indeks sensitivitas butir yang efektif berada diantara $0.00-1.00$. semakin besar indeks sensitivitas butir menunjukkan semakin besar keberhasilan pembelajaran (Ratumanan \& Laurens, 2011). Berdasarkan hasil yang diperoleh, maka dapat ditarik kesimpulan bahwa butir soal pada penelitian ini memberikan efek peningkatan pemahaman konsep siswa.

Data hasil tes thinking skill pada pretest diperoleh rerata 13 dengan kategori Kurang dan pada posttest diperoleh rerata 96 dengan kategori sangat baik. Perhitungan $N$-gain menunjukan rata-rata 0,96 dengan kriteria tinggi. Hasil tes thinking skill bisa dilihat pada Gambar 3 berikut ini:

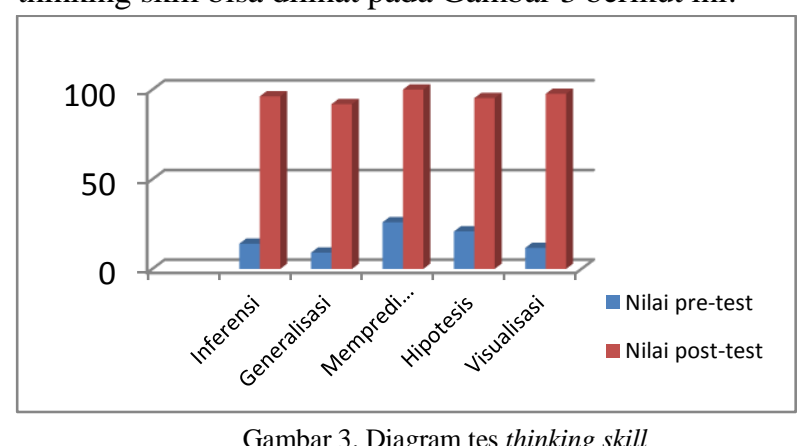

Tes thinking skill dilakukan peneliti sebanyak dua kali bersamaan dengan tes pemahaman konsep, yakni pretest dan posttest. Soal tes thinking skill yang digunakan adalah soal bentuk uraian, adapun indikator yang diujikan adalah inferensi, memprediksi, generalisasi, visualisasi, dan membuat hipotesis. Peningkatan rata-rata indikator thinking skill siswa adalah 0,96 dengan kategori tinggi. Nilai peningkatan thinking skill peserta didik saat posttest menunjukkan bahwa pembelajaran yang dilaksanakan guru berlangsung dengan baik dan dapat meningkatkan thinking skill peserta didik.

Selain kognitif siswa, social skill siswa juga dinilai.Pada penelitian ini social skill yang dikembangkan encouraging dan accepting ideas. Encouraging dengan tiga indikator yang dilatihkan yaitu: 1) berusaha mengetahui kegiatan penyelidikan dengan cara membaca buku; 2) berusaha mengetahui penyelidikan dengan cara bertanya; 3) antusias pada proses sains. Sedangkan accepting ideas memiliki tiga indikator yang dilatihkan yaitu: 1) mampu berargumentasi dalam rangka mempertahankan pendapat; 2) ide dikemukakan dengan suara yang lantang dan menggunakan kalimat yang mudah dipahami.; 3) mau menerima masukan jika masukan ditentang. Dari hasil pengamatan diperoleh rata-rata dari

\section{Pengembangan Perangkat Pembelajaran Model}


pertemuan 1, pertemuan 2 dan pertemuan 3 masingmasing 1,97 (Cukup), 2,82 (Baik) dan 3,61 (Sangat Baik). Secara ringkas dapat dilihat pada Gambar 4.

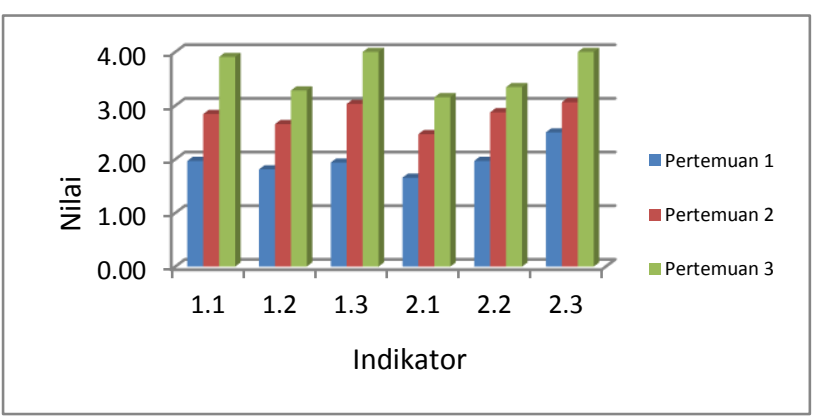

Gambar 4. Diagram pengamatan social skill siswa

Keterangan :

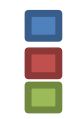

$=$ nilai social skill pada pertemuan 1

$=$ nilai social skill pada pertemuan 2

= nilai social skill pada pertemuan 3

$\mathbf{1 . 1}=$ Berusaha mengetahui kegiatan penyelidikan dengan cara membaca buku

1.2 = Berusaha mengetahui penyelidikan dengan cara bertanya

1.3 = Antusias pada proses sains).

2.1 = Mampu berargumentasi dalam rangka mempertahankan pendapat

2.2 = Ide dikemukakan dengan suara yang lantang dan menggunakan kalimat yang mudah dipahami

2.3 = Mau menerima masukan jika masukan ditentang

Hasil ini menunjukkan bahwa social skill terus meningkat sehingga pembelajaran dengan menggunakan model nested berbasis inkuiri terbimbing dapat menjadi sarana guru untuk dapat menyesuaikan pengalaman belajar, sumber daya, kebutuhan yang disesuaikan dengan kemampuan masing-masing siswa.

\section{PENUTUP}

\section{A. Simpulan}

Berdasarkan hasil penelitian yang telah dilakukan, maka dapat disimpulkan bahwa perangkat pembelajaran IPA model nested berbasis inkuiri terbimbing pada materi indra penglihatan dan alat optik yang dikembangkan layak untuk digunakan dalam pembelajaran dan dapat meningkatkan pemahaman konsep, thinking skill dan social skill siswa SMP Kelas VIII.

\section{B. Saran}

Mengimplementasikan Inovasi Pembelajaran. Surabaya: PSMS UNESA.

Ratumanan \& Laurens. (2011). Penilaian Hasil Belajar pada Tingkat Satuan Pendidikan Edisi2. Surabaya: Unesa University Press.
Beberapa saran dapat dikemukakan oleh peneliti berdasarkan penelititan yang telah dilakukan adalah sebagai berikut:

1. Persiapan yang matang dan pengelolaan waktu yang maksimal dengan menggunakan pembelajaran IPA model nested berbasis inkuiri terbimbingsehingga semua siswa aktif dalam pembelajaran.

2. Perangkat pembelajaran IPA model nested berbasis inkuiri terbimbing yang dihasilkan dapat digunakan sebagai acuan bagi guru untuk mengembangkan perangkat pembelajaran pada materi pokok maupun mata pelajaran yang lain.

\section{DAFTAR PUSTAKA}

Arends, R. (2012). Learning to teach, 9th edition. New York: Mc-Graw Hill.

Branch, J. and Oberg, D. (2004). Focus on inquiry a teacher guide to implementing inquiry based learning. Canada: Alberta Education, Alberta.

Borich, G. D. (1994). Observation Skills for Effective Teaching. The University Of Texas: USA.

Depdiknas. (2003). Undang-undang Nomor 20 Tahun 2003 tentang Sistem Pendidikan Nasional. Jakarta: Pemerintah Republik Indonesia.

Gronlund, N. E.and Linn, R. L.(1995).Measurement and assesment in teaching(7th ed). New Jersey: Merril Englewood Cliffs.

Hake.(1999). Analyzing change/gain scores. (Online). Tersedia http://www.physicsindiana.edu/sdi/ Analyzing-Change-Gain. pdf.

Ibrahim, M. (2010). Dasar-dasar Proses Belajar Mengajar. Surabaya: Unesa Univesity Press.

Kemendikbud. (2015). Peraturan Menteri Pendidikan dan Kebudayaan Nomor 53 Tentang Penilaian Hasil Belajaroleh Pendidik dan Satuan Pendidik pada Pendidikan Dasar dan Pendidikan Menengah. Jakarta: Depdiknas

Levine \& Ornstein. (1985). An introduction to The Foundations of Education. $3^{\text {rd }}$ Edition. Boston: Houghton Mifflin Company.

Nur, M. (2012). Pengembangan Bahan Ajar untuk Memberi Kemudahan Guru

Riduwan. (2010). Skala Pengukuran Variabel-Variabel Penelitian cetakan ke VII. Bandung: Alfabeta. 
Sugiyono. (2013). Metode Penelitian Pendidikan Pendekatan Kuantitatif, Kualitatif dan $R \& D$. Bandung: Alfabeta.
Thiagarajan, S., Semmel.D.S. \& Semmel,M.I. (1974). Instructional Development for training teacher of Exceptional Children a Sourcebook.Bloomington: Center for Innovation on teaching the Handicape 